\title{
Effect of Implementing A Clinical Pathway Directed Care on the Frequency of Complication Related Traumatic Brain Injury
}

\author{
Warda Ramadan Abouzeid ${ }^{1}$, Nagwa Ahmad Reda ${ }^{2}$, Mohammad Mohamed Abd-Ellatif ${ }^{3}$, Mona Aly \\ Mohammed $^{4}$, Mervat Anwar Abd-Elaziz ${ }^{5}$ \& Matthew J Leach ${ }^{6}$. \\ 1. Assistant Lecturer of Critical Care and Emergency Nursing, South Valley University, Visiting International \\ Research (PhD) Student, University of South Australia, Australia, Egypt. \\ 2. Professor of Critical Care and Emergency Nursing, Alexandria University, Egypt. \\ 3. Professor of Anesthesia, faculty of medicine, Assiut University, Egypt. \\ 4. Assist. Professor of Critical Care and Emergency Nursing, Assiut University, Egypt. \\ 5. Assist. Professor of Critical Care and Emergency Nursing, Assiut University, Egypt. \\ 6. Assist. Professor of Rural Health, PhD Senior Research Fellow, University of South Australia, Australia.
}

\begin{abstract}
Background: Severe traumatic brain injury (STBI) is a serious medical condition that is associated with considerable disease burden and disability throughout the world. Clinical pathways provide the means to connect the best available evidence with clinical practice to improve patient outcomes. Objective: To measure the effectiveness of implementing a clinical pathway to usual care on the complications related to severe traumatic brain injury. Design: Quasi-experimental study.Methods: A convenience sampling of 60 adult patients with TBI were recruited, with 30 patients assigned to the control group and 30 to the pathway group. The study was conducted at the trauma ICU of Assiut Hospital, Egypt. The control group received 15 days of ICU routine care and intervention group received 15 day of care includes in the clinical pathway. Results: The study found fewer complications related to TBI in the clinical pathway group, with statistically significant differences found between groups. Patients in the clinical pathway group demonstrated significantly fewer cases of prolonged mechanical ventilation and reintubation. Conclusion: The current study suggests that the implementation of a clinical pathway for severe TBI may be effective in decreasing the frequency of complications related to severe TBI.
\end{abstract}

Keywords: Clinical Pathway, Severe Traumatic Brain Injury, Complications, Mechanical Ventilation \& re-Intubation.

\section{Introduction}

Brain injuries account for nearly one third of all deaths, which result from a traumatic injury (Cuthbert et al., 2015) The causes of head injury are numerous with common causes of motor-vehicle traffic crashes or transportation accidents. The half of all TBIs involving crashes cars, motor bicycles, bicycles, pedestrians and falls (Frieden et al., 2015). Almost half brain injury involves alcohol use; in Australia between 2000-2012 around 90 cases involved in fatal head injury result from King hits (one punch) after alcohol or drugs use (Pilgrim et al., 2014).

Traumatic brain injury varies in severity, patient characteristics and affected area, and the type of trauma (non-penetrating or penetrating, focal or diffuse). Most treatments and management of TBI do not targeted primary injury but rather aim to prevent secondary insults resulting from the injury. Several standards are used for classifying TBI include mechanism of injury, severity of injury, pathophysiology and pathoanatomy. Injury severity is the most common classification and is dependent on many features identified by the neurological examination through the Glasgow Coma Scale, duration of unconsciousness and post-traumatic amnesia (Ramon \& Vos, 2015)

The management of severe TBI is complex, challenging and often necessitates a multimodal, standardised approach. This approach generally includes circumspective haemodynamic monitoring and support, fluid and electrolyte management, respiratory therapy and other aspects of care that focus on preventing secondary brain injury, improving cerebral oxygenation and maintaining adequate cerebral perfusion pressure. The management of severe TBI also requires collaboration across multiple disciplines, including the involvement of critical care nurses, neurointensivists, neurosurgeons, respiratory therapists and other medical specialties (Haddadsm, 2010).

Clinical pathways have been developed in the health care system as multidisciplinary care plans that outline the sequence and timing of actions necessary for achieving expected patient outcomes and organizational goals regarding quality, costs, patient satisfaction and efficiency (De-Luc et al., 2001) The development and implementation of the clinical pathways increases collaboration between the disciplines, professionals and agencies. This ensures continuity of patient care by reducing unnecessary 
variations in the management of the patient and to support clinical effectiveness, clinical audit and risk management (De-Bleser et al., 2006).

Today, Clinical pathways are usually interdisciplinary in focus, merging the medical and nursing plans of care with those of other disciplines, such as physical therapy, nutrition, or mental health. They provide opportunities for collaborative practice and team approaches that can maximize the expertise of multiple disciplines (Vanhaecht et al., 2007).

Critical care nurses can be very proactive for patients with severe traumatic brain injury. Critical care nurses are responsible for both management and recording of hospitalization related outcomes. Therefore, a high level of nursing knowledge and skills is required to achieve effective and safe management with regard controlling the side effect of treatment. Many researchers concluded and recommended that nursing practice should attempt to prevent, or minimize the complication related hospitalization (Lau, 2014).

\section{Subjects \& Methods \\ Subjects}

Research design: a quasi-experimental research design has been used in this study. This design is used to explain relationship, clarify certain events happened or both. This type of experimental design in which the researcher has limited control over the selection of study participants. In clinical nursing studies, subjects are frequently not randomly selected but the samples are convenient. Thus, nurse researchers conduct more quasi-experimental studies.

\section{The Aim of the study}

The study was designed to investigate whether the implementation of the clinical pathway for patients with severe traumatic brain injury improves the neurological variance of clinical care, complication rate, and duration of mechanical ventilation, when compared to usual care.

\section{Hypotheses}

Patients managed under the traumatic brain injury clinical pathway:

- Exhibit significantly fewer complications related to TBI than those receiving usual care [e.g. immediate seizures, hydrocephalus, cerebral spinal fluid (CSF) leaks and seizure]

- Demonstrate significantly fewer diagnostic variances than those receiving usual care (control).

- Exhibit a significantly shorter duration of mechanical ventilation and re-intubation than those receiving usual care (control)

\section{Significance of the study}

The setting of the study was selected because of its high flow of head injury patients with 160 patients admitted to the trauma ICU with traumatic brain injury every year (Assiut university hospital records, 2013) The unit also contains the necessary resources such as advanced diagnostic machines (MV, X-rays, and laboratory investigation), infection control system and qualified persons to implement the clinical pathway.

\section{Setting}

The study was conducted at the trauma intensive care unit (ICU) of the Main Assiut University Hospital. The unit provides care for all types of trauma patients, including those with head and spinal cord injuries and chest trauma.

\section{Study group}

60 adult critical ill patients based on epi info power analysis with a two-tailed alpha level set at 0.05 . The sample recruited equally into two groups; control and intervention group (30 patients each). The control group started first then the intervention group.

Educational/ training sessions were provided to the care providers about the purpose and process of implementing the pathway for one week after collecting data of the control group. The training was through power point presentation, discussion and giving hand-out of the clinical pathway. Also, the staff was encouraged to ask questions in a small group setting.

After completion of the recruitment and screening, all patients admitted to the trauma unit during the four months' period from first of January 2015, until the end of April 2015, were assessed and managed as intervention group. The intervention contained 30 patients and met the designed criteria.

\section{Participant inclusion criteria}

- Aged 18-60 years: This age group was selected because it represented an adult population that is likely to require a similar approach to TBI management.

- Glasgow coma scale score (GCS) between 3 and 8: The GCS measures severity of traumatic brain injury. Severe brain injury (the scope of this study) is defined as a trauma to the head that results in a loss of consciousness of greater than 24 hours, an initial Glasgow Coma Scale of 3 - 8, and a posttraumatic amnesia period of greater than seven days

- Non-penetrating head injury: non-penetrating head injuries are the most common injury accounts for about $75 \%$ of all head injury cases.

\section{Methods}

Development of the clinical pathway

Development of the severe traumatic brain injury clinical pathway began with critical review of the 
relevant literature. The clinical pathway comprised of two instruments: the traumatic brain injury assessment checklist (tool I) and the patient progress variances checklist (tool II). The traumatic brain injury assessment checklist was designed to assess patients in both study groups. The patient progress variances (tool II) checklist was designed to address all the process of patients' intervention. This tool was divided into three stages of the patient intervention; stage I: admission to the ICU (the first $24 \mathrm{hrs}$.) it included standardised order sheet to assess the patient's condition and to give management during first day, stage II: the acute care (the next 7 days), it included patient progress variance checklist which cover the assessment and intervention during acute stage and stage III: mobility and weaning (the last 7 days of the study) which included multi-disciplinary intervention during the weaning stage. The scoring included done or not done.

The current clinical pathway developed by the researcher in cooperation with physicians, nurses, pharmacists, and other related healthcare professionals of the trauma unit at Assiut University Hospital. This study measured the effects of a clinical pathway that provided high quality of care to decrease complications related to TBI, decrease neurological variance and decrease duration of mechanical ventilation and re-intubation.

\section{Pilot testing of the intervention}

The pilot study was conducted within same trauma unit as the main study, but recruited only six critically ill patients (intervention group only), or $10 \%$ of the total sample size. The pilot study was similar in every other way to the main study, including the inclusion/ exclusion criteria, fifteen days for intervention, and the same tools were used also as the main study. The tools were tested for reliability using Cronbach's alpha reliability method on a sample of six subjects. The correlation coefficients were; $(r)=84.3 \%$ for the Traumatic brain injury assessment tool, $73.8 \%$ for the Clinical Pathway Patient progress variances checklist, $73.8 \%$ for the patient clinical outcomes evaluation tool and $91.2 \%$ for the patient's/ family satisfaction tool.

\section{Control group}

The control group contained 30 patients with the same designed criteria and received routine daily management of the hospital. Data was collected first from the control group for about three months then collected from the intervention group, to avoid data contamination. For the control group, the three designed study tools used to assess the patients daily and detect the variances in management and outcomes than the designed clinical pathway.

\section{Results}

Table (1): Events leading to TBI and participant history by study group.

\begin{tabular}{|c|c|c|c|c|c|}
\hline Clinical data & \multicolumn{2}{|c|}{ Study } & \multicolumn{2}{|c|}{ Control } & \multirow[t]{2}{*}{ P value } \\
\hline Event leading to TBI & $\mathrm{n}$ & $\%$ & $\mathrm{n}$ & $\%$ & \\
\hline Motor accidents & 21 & 69.9 & 20 & 66.3 & \multirow{5}{*}{0.205} \\
\hline Falling from height & 6 & 20.0 & 2 & 6.7 & \\
\hline Assault from other & 2 & 6.6 & 6 & 20.0 & \\
\hline Firearm injury & 1 & 3.3 & 0 & 0.0 & \\
\hline Falling on ground & 0 & 0.0 & 2 & 6.7 & \\
\hline \multicolumn{6}{|l|}{ Past medical history } \\
\hline Non & 26 & 86.7 & 25 & 83.3 & \multirow{5}{*}{0.974} \\
\hline Hypertension & 2 & 6.7 & 3 & 10.0 & \\
\hline Diabetes Mellitus & 1 & 3.3 & 1 & 3.3 & \\
\hline Heart Disease & 1 & 3.3 & 1 & 3.3 & \\
\hline Poly-trauma & 28 & 93.3 & 26 & 86.6 & \\
\hline
\end{tabular}


Table (2): Baseline Revised Trauma Score (RTS), by study group.

\begin{tabular}{|c|c|c|c|c|c|}
\hline Revised Trauma Score & \multicolumn{2}{|c|}{ Study } & \multirow{2}{*}{$\frac{\text { Control }}{\mathrm{n}}$} & \multirow[b]{2}{*}{$\%$} & \multirow[t]{2}{*}{$P$ value } \\
\hline Glasgow Coma Scale (GCS) & $\mathrm{n}$ & $\%$ & & & \\
\hline $3($ score $=0)$ & 2 & 6.7 & 0 & 0.0 & \multirow{5}{*}{0.379} \\
\hline $4-5($ score $=1)$ & 8 & 26.7 & 8 & 26.7 & \\
\hline $6-8($ score $=2)$ & 19 & 63.3 & 21 & 70.0 & \\
\hline $9-12($ score $=3)$ & 1 & 3.3 & 0 & 0.0 & \\
\hline $13-15($ score $=4)$ & 0 & 0.0 & 0 & 0.0 & \\
\hline \multicolumn{6}{|l|}{ Systolic Pressure (mmHg) } \\
\hline $0($ score $=0)$ & 0 & 0.0 & 0 & 0.0 & \multirow{5}{*}{0.959} \\
\hline $1-49($ score $=1)$ & 0 & 0.0 & 0 & 0.0 & \\
\hline $50-75($ score $=2)$ & 0 & 0.0 & 0 & 0.0 & \\
\hline $76-89($ score $=3)$ & 4 & 13.3 & 4 & 13.3 & \\
\hline$>89($ score $=4)$ & 26 & 86.7 & 25 & 83.3 & \\
\hline \multicolumn{6}{|c|}{ Respiratory Rate (breath/minute) } \\
\hline $0($ score $=0)$ & 0 & 0.0 & 0 & 0.0 & \multirow{5}{*}{0.548} \\
\hline $1-5($ score $=1)$ & 0 & 0.0 & 0 & 0.0 & \\
\hline $6-9($ score $=2)$ & 1 & 3.3 & 0 & 0.0 & \\
\hline$>29($ score $=3)$ & 3 & 10.0 & 2 & 6.7 & \\
\hline $10-29($ score $=4)$ & 26 & 86.7 & 27 & 90.0 & \\
\hline $\begin{array}{l}\text { *Revised Trauma Score(RTS), } \\
\text { mean }+ \text { SD }\end{array}$ & & $9 \pm 1.5$ & & $9.2 \pm 1.4$ & 0.412 \\
\hline
\end{tabular}

*The Revised trauma score=is the sum of the Glasgow Coma Scale, Systolic Blood Pressure and Respiratory Rate scores.

Table (3): Medications prescribed over the 15-day study period, by study group.

\begin{tabular}{|c|c|c|c|c|c|}
\hline \multirow{2}{*}{ Current medications } & \multicolumn{2}{|c|}{ Study } & \multicolumn{2}{|c|}{ Control } & \multirow{2}{*}{$P$ value } \\
\hline & $\mathbf{n}$ & $\%$ & $\mathbf{n}$ & $\%$ & \\
\hline \multicolumn{6}{|c|}{ Use of Muscle relaxants } \\
\hline Dormicum (Midazolam) & 12 & 39.9 & 7 & 26.7 & \multirow{5}{*}{0.273} \\
\hline Dormicum (Propofol, Deprivan) & 7 & 22.3 & 7 & 23.3 & \\
\hline Propofol (Deprivan) & 4 & 13.3 & 6 & 20.0 & \\
\hline Propofol\& Morphine & 1 & 3.3 & 0 & 0.0 & \\
\hline No muscle relaxants prescribed & 6 & 19.7 & 10 & 33.4 & \\
\hline \multicolumn{6}{|c|}{ Analgesics } \\
\hline Ketolac \& Perfalgan & 12 & 40.1 & 6 & 20.0 & \multirow{5}{*}{0.059} \\
\hline Perfalgan & 10 & 33.3 & 11 & 36.7 & \\
\hline Ketolac & 7 & 23.3 & 9 & 30.0 & \\
\hline Perfalgan \& Nalufin & 1 & 3.3 & 4 & 13.3 & \\
\hline No analgesics prescribed & 0 & 0.0 & 0 & 0.0 & \\
\hline \multicolumn{6}{|c|}{ Diuretics } \\
\hline Frusemide (Lasix) & 20 & 66.7 & 17 & 56.7 & \multirow{3}{*}{0.047} \\
\hline Mannitol & 10 & 33.3 & 8 & 26.7 & \\
\hline No diuretics prescribed & 0 & 0.0 & 5 & 16.7 & \\
\hline \multicolumn{6}{|c|}{ Antibiotics } \\
\hline Maxipime \& Nexium & 8 & 26.6 & 9 & 30.0 & \\
\hline Fortum\& Nexium & 7 & 23.3 & 3 & 10.0 & \\
\hline Cefobid & 5 & 16.7 & 3 & 20.0 & \multirow{5}{*}{0.082} \\
\hline Cefotax \& Nexium & 5 & 16.7 & 4 & 13.3 & \\
\hline Cefotax \&Unacyn & 4 & 13.3 & 9 & 20.0 & \\
\hline Unacyn & 1 & 3.3 & 2 & 6.7 & \\
\hline No antibiotics prescribed & 0 & 0.0 & 0 & 0.0 & \\
\hline
\end{tabular}


Table (4): Diagnostic procedures performed within the first 48 hours of study, by study group

\begin{tabular}{|c|c|c|c|c|c|c|c|c|c|c|}
\hline \multirow[b]{2}{*}{$\begin{array}{c}\text { Admission diagnostic } \\
\text { procedure }\end{array}$} & \multicolumn{4}{|c|}{ Study group } & \multicolumn{4}{|c|}{ Control group } & \multirow[b]{2}{*}{$\underset{\text { value }^{1}}{P}$} & \multirow[b]{2}{*}{$\begin{array}{c}\mathbf{P} \\
\text { value }^{2}\end{array}$} \\
\hline & $\begin{array}{c}1^{\text {st }} \text { day } \\
\text { of } \\
\text { study }\end{array}$ & $\begin{array}{c}\mathbf{2}^{\text {nd }} \\
\text { day } \\
\text { of } \\
\text { stud } \\
\mathbf{y}\end{array}$ & Done & $\begin{array}{l}\text { Not } \\
\text { done }\end{array}$ & $\begin{array}{c}\mathbf{1}^{\text {st }} \text { day } \\
\text { of } \\
\text { study }\end{array}$ & $\begin{array}{c}2^{\text {nd }} \\
\text { day } \\
\text { of } \\
\text { stu } \\
\text { dy }\end{array}$ & Done & $\begin{array}{l}\text { Not } \\
\text { done }\end{array}$ & & \\
\hline *Admission ABG & 30 & 0 & 30 & 0 & 30 & 0 & 30 & 0 & 1.000 & 1.000 \\
\hline Chest x-ray & 30 & 0 & 30 & 0 & 22 & 0 & 22 & 8 & 1.000 & 0.008 \\
\hline *CT scan C spine & 26 & 4 & 30 & 0 & 25 & 0 & 25 & 5 & 0.121 & 0.062 \\
\hline *T\& L spines X-ray & 26 & 4 & 30 & 0 & 25 & 0 & 25 & 5 & 0.121 & 0.062 \\
\hline CT scan of head & 30 & 0 & 30 & 0 & 30 & 0 & 30 & 0 & 1.000 & 1.99 \\
\hline
\end{tabular}

P. value ${ }^{I}$ : Comparison between intervention and control as $1^{\text {st }}$ and $2^{\text {nd }}$ day

$\boldsymbol{P}$. value $^{2}$ : Comparison between intervention and control done and not done, ABG: arterial blood gases, CT scan:

Computerized tomography, $\boldsymbol{T} \& \boldsymbol{L}$ spines: thoracic\& lumber spines $x$-ray.

Table (5): Frequency of prolonged mechanical ventilation and re-intubation, by study group

\begin{tabular}{|l|r|c|c|c|c|}
\hline \multirow{2}{*}{ Mechanical ventilation } & \multicolumn{2}{|c|}{ Study } & \multicolumn{2}{c|}{ Control } & \multirow{2}{*}{ P value } \\
\cline { 2 - 5 } & No & \% & No & \% & \\
\hline Prolonged MV & 9 & 30.0 & 15 & 50.0 & 0.188 \\
\hline Re-intubation & 5 & 16.7 & 14 & 44.0 & 0.026 \\
\hline
\end{tabular}

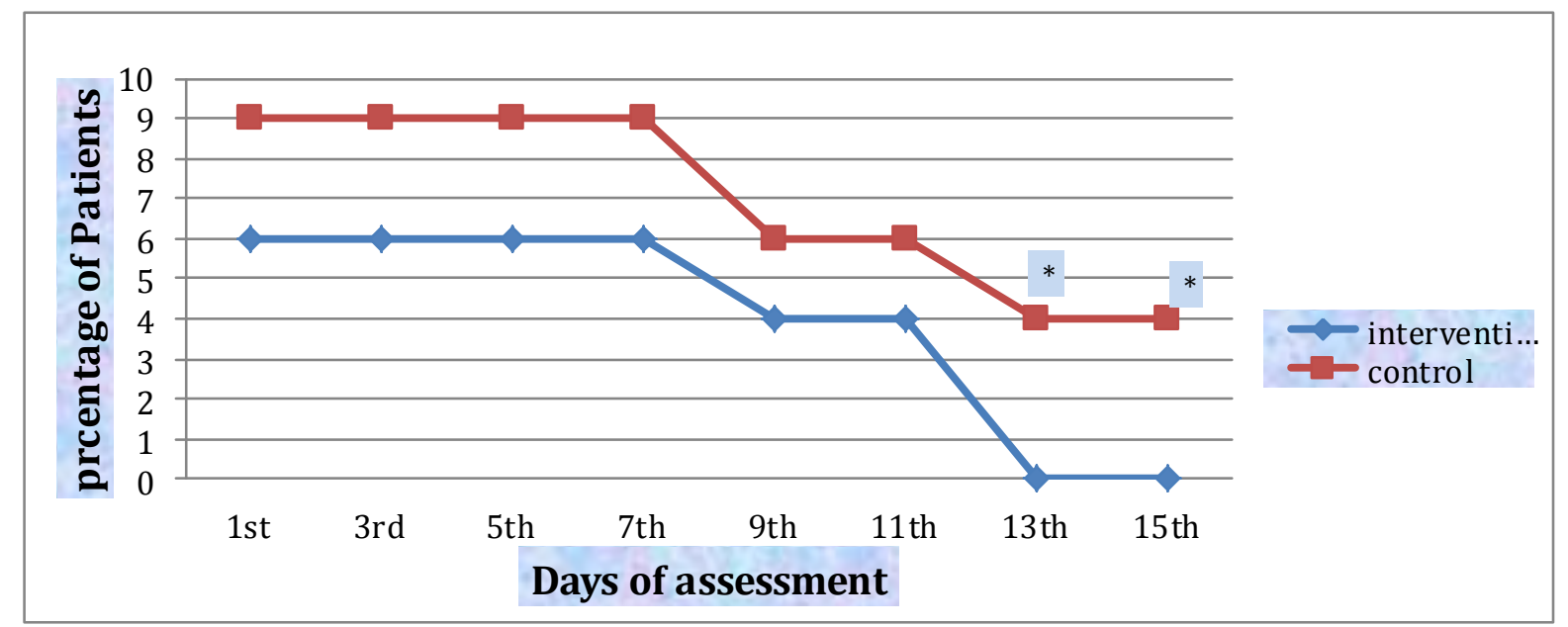

* significance at $p \leq 0.05$

Figure (1): frequency of occurrence of hydrocephalus over time, by study group 


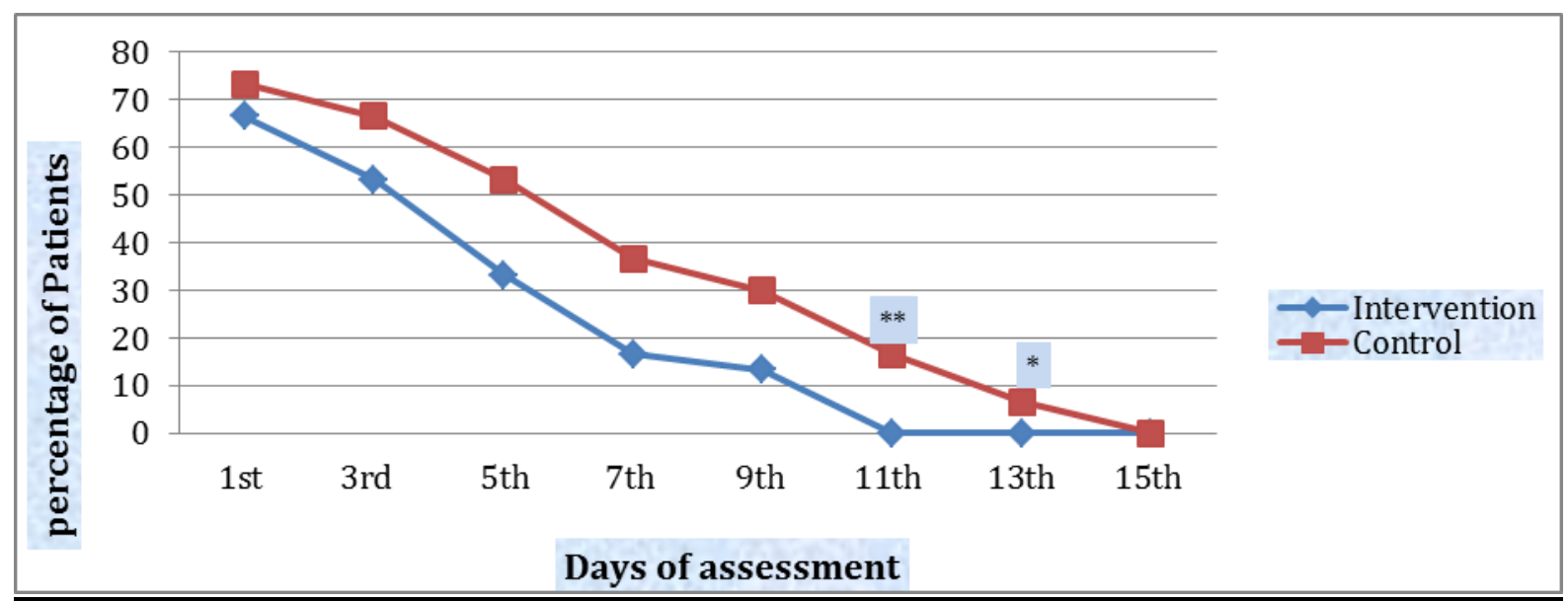

**significance at $p \leq 0.005, *$ significance at $p \leq 0.05$

Figure (2): frequency of occurrence of seizures over time, by study group

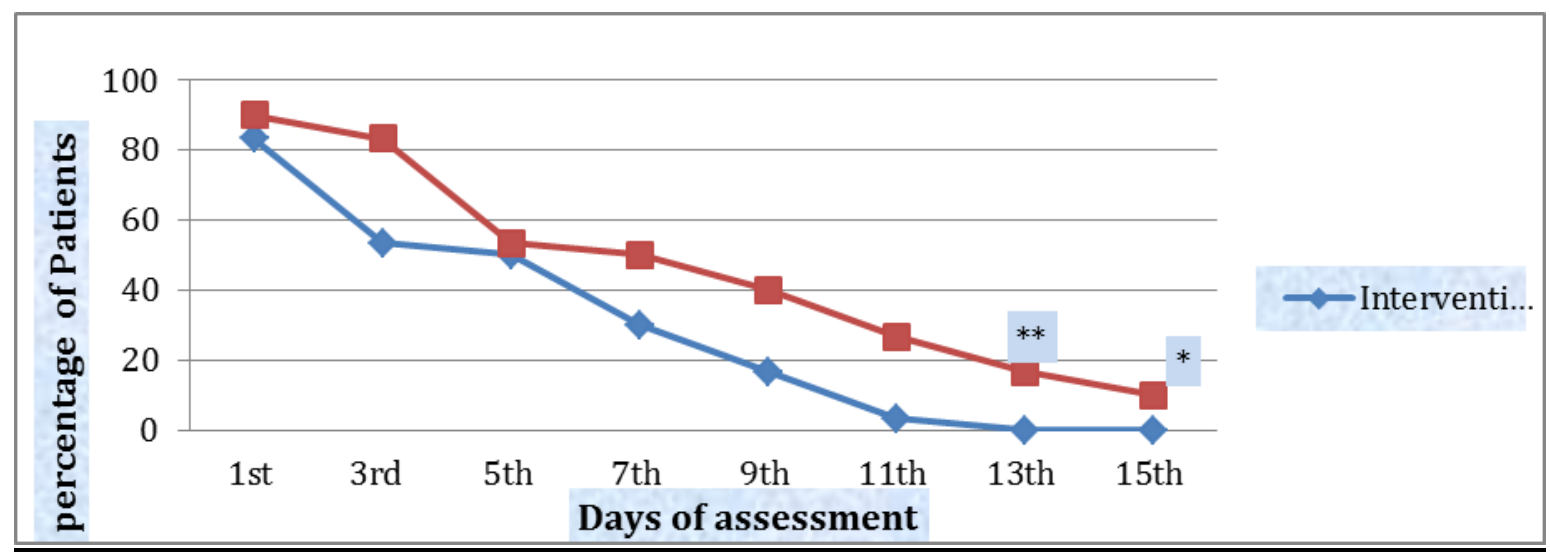

**significance at $p \leq 0.005, *$ significance at $p \leq 0.05$

Figure (3): frequency of occurrence of increased intracranial pressure over time, by study group

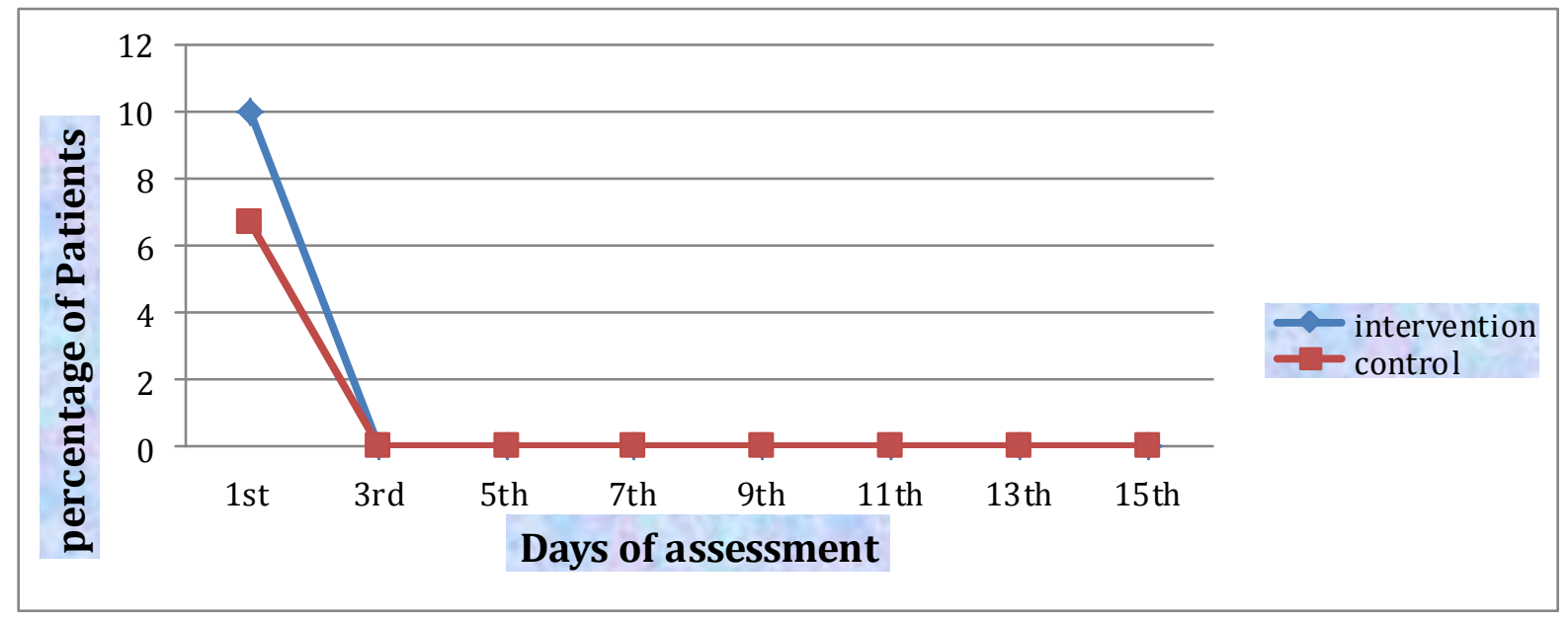

CSF = cerebrospinal fluid

Figure (4): frequency of CSF leakage over time, by study group 


\section{Demographic characteristics}

Participants in the intervention group were on average 10.7 years younger than those in the control group, with the difference in mean age between groups found to be statistically significant $(\mathrm{p}=0.001)$. There was also a difference in the marital status of participants in each group, with more patients in the intervention group being single (53.3\%), and a greater proportion of patients in the control group being married $(63.3 \%)$. However, differences in the marital status between groups were not statistically significant. Across both groups, most participants were male (represent 28 (93.3) in intervention group and 26 (86.7) in control group) and educated, with no statistically significant differences found between groups in relation to sex or the level of education.

\section{Clinical characteristics of the sample}

The events leading to TBI and participant medical history are reported in Table 1 . The event most likely to lead to TBI in both groups was motor car accidents, which represented $49.9 \%$ of cases in the intervention group and $56.3 \%$ of cases in the control group. There were no statistically significant differences between groups with regards to the type of event leading to traumatic brain injury.

In terms of past medical history, most patients $(>80 \%)$ had no co-morbidities. The number of patients with hypertension, diabetes mellitus and heart disease in each group was similar with no statistically significant difference found between groups. In addition, most patients in each group had poly-trauma on admission with no statistically significant difference found between groups.

The baseline revised trauma score (RTS) and scores of each component for each study group is reported in Table (2): Differences between study groups in the revised trauma score and RTS component scores were not statistically significant.

\section{Frequency of complications related to TBI}

The frequency of occurrence of hydrocephalus over the15-day is presented in Figure (1): Marginally significant differences between groups in the occurrence of hydrocephalus were evident at day 13( $\mathrm{p}=0.062)$ and day15 ( $\mathrm{p}=0.062)$ of the study

As shown in Figure (2): the frequency of occurrence of seizures in each group declined over the 15-day study period. A statistically significant difference between groups in the occurrence of seizures was evident at day $11(\mathrm{p}=0.002)$; differences between groups on day 13 were marginally significant $(\mathrm{p}=0.062)$.

The frequency of occurrence of increased intracranial pressure (i.e. $>15 \mathrm{mmHg}$ ) decreased in both study groups over the 15-day study period Figure (3). Statistical significant differences between groups in the occurrence of increased intracranial pressure were evident at day $13(\mathrm{p}=0.002)$, and day $15(\mathrm{p}=0.022)$ of the study.

Figure (4): Shows the frequency of cerebrospinal fluid (CSF) leakage declined in each study group over time. However, there were no significant differences in CSF leakage between both groups at any time point.

\section{Variances in medication}

Medications prescribed over the 15-day study period varied, by study group Table (3): However, the only significant difference between groups in medications prescribed was in relation to the use of diuretics $(\mathrm{p}=0.047)$, where there was more frequent use of Lasix and Mannitol in the intervention group.

\section{Variances in diagnostic procedures}

Table (4): Outlines the variances in diagnostic procedures performed within the first 48 hours of the study. All patients in the intervention and control groups experienced an arterial blood gas test and CT scan within the first 48 hours of the study. However, there were statistically significant differences between groups in the number of patients receiving other diagnostic tests, with significantly fewer patients in the control group experienced a chest $\mathrm{x}$ ray study $(\mathrm{p}=0.008)$. Differences between both groups in the number of patients experienced a CT scan of the spine $(\mathrm{p}=0.062)$ or thoracic and lumber $\mathrm{x}$ ray $(\mathrm{p}=0.062)$ were marginally significant.

Duration of mechanical ventilation and reintubation

Table (5): Shows the frequency of prolonged mechanical ventilation [defined as ventilation $>4$ days] and re-intubation in each study group. While there were relatively fewer cases of prolonged mechanical ventilation in the intervention group, the differences between both groups were not statistically significant. Statistical significant differences between both groups were evident in the frequency of reintubation $(p=0.026)$, with fewer cases reported in the intervention group than the control group.

\section{Discussion}

\section{The sample}

The study recruited sixty patients with TBI over a seven-month period, with thirty patients assigned to each group. In terms of the comparability of study groups at baseline, the intervention group was similar to the control group across most variables at baseline, including demographic characteristics (e.g. gender, marital status and level of education), clinical presentation (e.g. Glasgow coma scale and severity of injury) and type of event leading to traumatic brain injury. This suggests that the consecutive selection of subjects for participation in this study, and the nonrandom assignment of participants to treatment 
groups, did not introduce any observable biases (Anwar, 2010).

\section{Complications related to TBI}

Reducing morbidity in severe TBI and improving the rate and extent of recovery from this condition, are major challenges for clinicians (Liu, 2015). The diverse and complex nature of the pathological mechanisms activated by TBI suggests that multimodal interventions may be needed to improve patient recovery (Ruff \& Riechers, 2012). To test this assumption, the current study set out to determine whether the provision of a clinical pathway for STBI may assist in reducing TBI-related morbidity; specifically, the complications of this condition.

\section{Hydrocephalus}

Acute post-traumatic hydrocephalus (PTH) is an active and progressive process of excessive cerebrospinal fluid (CSF) accumulation due to liquordynamic disturbances following craniocerebral injury, and is a relatively frequent consequences of traumatic brain injury (Choi et al., 2008). In the postacute period following the onset of severe TBI, the incidence of hydrocephalus is quite variable and has been reported in four percent to fourth five percent of hospital patients in Denmark (Peter et al., 2013). PTH is a treatable complication of head injury with prompt treatment often leading to favorable outcomes (Nor, 2013). Therefore, it is recommended that the condition be promptly identified and aggressively managed (Sarkari et al., 2010).

The current study demonstrated a declining trend in the number of cases of hydrocephalus in both study groups over time, but statistically significant differences between groups (in favor of the intervention group) on days 13 and 15 of the study. It is unclear why the differences between groups were only evident on days 13 and 15 . It is possible that these findings could just reflect normal variations in the rate of improvement of hydrocephalus in the nonrandomized samples. Bhatoe \& Batish (2005) alluded to this point in their study of post traumatic hydrocephalus in Indian patients aged between 10 and 60 years, reporting that some patients show rapid and complete regression of cognitive impairment, while others show slow improvement over a period of weeks or months.

\section{Intracranial hypertension}

Intracranial pressure (ICP) is the total pressure exerted by the brain, blood and CSF in the intracranial vault (Rangel-Castillo et al. 2008). Patients with severe traumatic brain injury have a greater than fifty percent chance of developing intracranial hypertension (i.e. ICP>15 $\mathrm{mmHg}$ ) (Biersteker et al., 2012). Intracranial hypertension is the final common pathway that leads to death or disability in most acute cerebral conditions; the two major consequences of increased ICP being: brain shifts and brain ischemia (Roytowski, 2013). Close monitoring and prompt treatment of raised ICP are therefore critical elements of the clinical management of severe traumatic brain injury (Biersteker et al., 2012).

Similar to PTH, the number of cases of intracranial hypertension also reduced in both groups over time, with statistically significant differences observed between groups (in favor of the intervention) on days 13 and 15 of the present study. However, the days at which these differences between groups occurred cannot be explained. As with PTH, the findings could be an artefact or a product of the variability of this complication (Sankhyan et al., 2010). It is also possible that other factors contributing to increased ICP, which were not measured or controlled for in the current study, may have been present. These factors may include systolic blood pressure below $90 \mathrm{~mm}$ $\mathrm{Hg}$, patients age over 40 years, unilateral or bilateral motor accident, and reformation of mass lesions after evacuation (such as epidural hematomas, acute subdural hematoma, and hemorrhagic contusions)

(Rangel-Castillo et al., 2008).

\section{Seizure}

Post traumatic seizure (PTS) disorder is a clinical manifestation that is presumed to be the result of an abnormal and excessive discharge of a set of neurons in the brain. It can be further classified as immediate (within 24 hours of injury onset), early ( $<1$ week after injury) or late ( $>1$ week after injury) (Teasell et al., 2007).

The risk of developing seizures following a brain injury is directly related to the severity of the injury, that is, the more severe the injury, the higher the risk of developing seizures (Cesnik et al., 2013) The prophylactic use of anti-epileptic drugs (AED) is shown to be effective in controlling early triggered seizures, mainly by blocking or delaying epileptogenic mechanisms established after TBI (Chen et al., 2009). In the clinical pathway, the close monitoring of seizures duration and the focus on using of the anti-epileptic drugs (Midazolam) up to one week after TBI were relatively effective in controlling the incidence of seizures.

In the current study, the occurrence of seizures declined in both groups over the 15-day study period, with a marginally significant difference found between groups on day 13, in favor of the clinical pathway groups. The absence of a statistically significant difference between groups for most time points may relate to the similar approaches used for seizure prophylaxis/ management in both groups. The presence of a significant between-group difference on day 13 is unusual however; as such, a definitive 
explanation cannot yet be given. It may be the case that the significant finding at this time point is just an artefact. Whatever the reason, further investigation with a much larger sample is needed to shed some light on the effectiveness of clinical pathways in improving seizure occurrence.

\section{Cerebrospinal fluid leakage}

Cerebrospinal fluid (CSF) rhinorrhoea or otorrhea is indicative of an abnormal communication between the subarachnoid space and the nasal cavity or tympanomastoid space. Eighty percent of the cerebrospinal fluid (CSF) leaks occur following nonsurgical trauma, and $12 \%$ to $30 \%$ of all basilar skull fractures (Prosser et al., 2011) The presence of a CSF leak can be dangerous, leading to potentially life-threatening complications such as meningitis. More than $50 \%$ of CSF leaks are evident within the first two days of trauma, and $70 \%$ within the first week (Prosser et al., 2011) Data suggest that early identification, management and surgical repair $(<7$ days) of CSF can reduce the risk of meningitis and improve patient outcomes, including mortality and morbidity rate (Ibrahim et al., 2016).

The current study found the number of cases of CSF leakage declined in both study groups over time, with no significant differences between-group identified at any time point. The lack of a significant difference between groups may be attributed to the strategies used in the control and intervention group to manage CSF leakage (strict bed rest, elevation of the head, and avoidance of straining, nose blowing and Endoscopic endonasal repair) were not too dissimilar from each other.

Overall the finding of the current study shows that the STBI clinical pathway may decrease the occurrence of complications such as post-traumatic hydrocephalus, intracranial hypertension, seizure and cerebrospinal fluid leakage.

\section{Occurrence of clinical variances}

A clinical variation is described as a detour from the patient care activities outlined in a clinical pathway (Evensen et al., 2010). These detours can occur at individual, discipline and organisational levels, and aligns with what the National Institute of Clinical Studies (NICS) refers to as "knowing-doing gaps" or variances (Kennedy, 2010). For this reason, clinical pathways differ from practice guidelines, protocols and algorithms as they are designed to accommodate for variances in clinical practice in that they; allow for deviations to be documented, analysed and managed (Rotter et al., 2010).

\section{Variances in prescribed medications}

Critically ill patients are prescribed twice as many medications as patients outside of the intensive care unit; patients with traumatic brain injury (TBI) are no exception (Moyen et al., 2008) In the current study, the only significant difference between groups in medications prescribed was in relation to the use of diuretics, where there was more frequent use of Lasix and Mannitol in the intervention group than in the control group. As a result, there was a decreased in the level of intracranial hypertension over time among patients in the pathway group. This result is consistent with the most recent Brain Trauma Foundation guidelines, which support the use of Mannitol as a first line hyperosmotic agent for ICP (Bhat et al., 2008).

One of the more challenging aspects of caring for persons with traumatic brain injury (TBI) is the management of the agitated patient; this is because agitated patients can resist direct care, be disruptive on the unit, and/or pose a physical risk to themselves, family, or staff (Lombard \& Zafonte, 2005) This study found, a higher percentage of sedation and analgesic use among patients in the clinical pathway group compared to those in the control group. This may suggest a higher rate of agitation among patients in the pathway group. On the other hand, it may indicate greater adherence to best practice.

Variances in diagnostic procedures

The best practice for the diagnosis of TBI is to perform the diagnostic measures earlier as possible and use the suitable methods such as brain imaging with CAT scan, and magnetic resonance imaging (MRI) (Pandor et al., 2011). In the current study, all patients in the intervention and control groups experienced an arterial blood gas test and CT scan within the first 48 hours of the study. This may relate to that all health care staff in the ICU oriented about the importance of performing arterial blood gas test and CT scan within the first 48 hours for patients with severe traumatic brain injury. However, there were statistically significant differences between groups in the number of patients receiving other diagnostic tests, such as a chest x-ray, a CT scan of the spine or thoracic and lumber $\mathrm{x}$-ray with significantly fewer patients in the control group. This may be related to that the using of standardized diagnostic order sheet on admission for all pathway groups result in decreased number of variances among the intervention group in the diagnostic studies in the first 48 hours compared to the control group.

\section{Variances in invasive device duration}

Invasive medical devices play an essential role in the monitoring and management of critically ill patients. However, the presence of an indwelling invasive device is a recognized risk factor for healthcare associated infection (HAIs), such as; ventilatorassociated pneumonia, central venous catheter related bloodstream infections and catheter-associated urinary tract infections (Loveday et al., 2014). 
Healthcare associated infections are the major cause of patient morbidity and mortality in developed countries and represent the greatest threat in the ICU (by increasing length of stay and health care costs). In order to decrease invasive device-associated hospital infection rates, it is recommended that clinical staff maintain ongoing surveillance of infection, avoid unnecessary mechanical ventilation and indwelling catheter use, and detach patients from ventilators and other invasive devices as soon as possible (Evik et al., 2013). The clinical pathway developed for this study incorporated a number of practices to reduce the risk of HAI, as informed by clinical practices guidelines. This included hand hygiene and the use of personal protective equipment to prevent contact transmission, disposal of single-use sharps, reprocessing of reusable medical instruments and equipment, use of surface barriers to protect clinical surfaces, staff teaching, and periodic surveillance.

The current study found invasive devices to be insitu for a relatively shorter period of time in the intervention group than the control group. This suggests that there was greater adherence to best practice in the intervention group, possibly translating to a lower risk of harm from invasive device-associated hospital infection among participants in this group. The impact of clinical pathways on infection rates has also been demonstrated by (Walker et al., 2012), who showed the introduction of a bronchiolitis clinical care pathway to be effective in reducing the proportion of infants with infection and the use of prescribed salbutamol from $50 \%$ to $8 \%$. In a systematic review and meta-analysis of the effects of clinical pathways on length of stay, hospital costs and patient outcomes, (Rotter, et al., 2008) reported a significant reduction in the duration of invasive devices. Both of these studies corroborate the findings of the current study, thus supporting the value of clinical pathways in reducing healthcare associated infection.

\section{Duration of mechanical ventilation and re- intubation}

Mechanical ventilation is an essential therapeutic for patients with severe TBI, as it aims to protect the airway (via endotracheal intubation) in order to prevent hypoxemia and hypercapnia whilst a patient is receiving heavy sedation - the purpose of which is to mitigate the risk of complications and to facilitate recovery (Tülin \& Nihan, 2012). However, the provision of mechanical ventilation for periods exceeding three days is undesirable as it can result in complications such as infection (e.g. ventilatorassociated pneumonia), barotrauma, airway haemorrhage and depression of the laryngopharyngeal reflexes (White, 2012).
The current study revealed relatively fewer cases of prolonged mechanical ventilation (MV) in the intervention group when compared to the control group. Likewise, there were significantly fewer cases of re-intubation reported in the intervention group than the control group. These findings are consistent with those reported by Anwar (2010), who found the implementation of a clinical pathway in 60 patients undergoing cardiac valvular surgery resulted in earlier extubation times and fewer cases of reintubation when compared with control. This suggests that clinical pathways may be effective in preventing prolonged $\mathrm{MV}$ and re-intubation in patients with STBI.

\section{Limitations}

There are number of limitations to this study that may affect the interpretation and generalizability of the findings. The short duration of the study may be perceived as a study limitation. In particular, fifteen days may be considered a short duration for the management of severe traumatic brain injury as it may not provide sufficient time to detect clinically or statistically significant differences between groups for all relevant outcomes, including long-term outcomes.

\section{Conclusion \& Recommendations}

Traumatic Brain Injury can be fatal if it is not promptly diagnosed and treated; even with timely treatment, some patients can still sustain to serious permanent neurologic deficits. Findings of the present study suggest that the clinical pathways may be instrumental in improving the patient experience, reducing disease burden and decreasing health care expenditure. Additional research is also needed to examine the impact of clinical pathways with study period longer for detecting clinically and statistically differences in the outcomes of patients with severe TBI.

\section{References}

1. Anwar S., (2010): The outcome of implementing a clinical pathway for patients undergoing cardiac valvular surgery. (Unpublished) Doctoral thesis, Alexandria University, Faculty of Nursing.

2. Bhat R., Hudson K., \& Sabzevari T., (2008): An Evidence-Based Approach To Severe Traumatic Brain Injury. Emergency Medicine Practicej. 10 (12):1-24.

3. Bhatoe H., \& Batish V., (2005): Post head injury hydrocephalus. Indian Journal of Neurotrauma (IJNT); 2(2): pp. 131-133.

4. Biersteker H., Andriessen T., Horn J., Franschman G., Naalt J., Hoedemaekers C., Lingsma H., Haitsma I., \& Vos P., (2012): 
Factors influencing intracranial pressure monitoring guideline compliance and outcome after severe traumatic brain injury. Crit Care Med; 40 (6); pp. 1914- 1922

5. Brain Trauma Foundation, American association of neurological surgeons, and congress of neurological surgeons. (2007): Guidelines for the management of sever traumatic brain injuryJournal of Neurotrauma 24 (1); S1- S106.www.braintrauma.org

6. Cesnik E., Casetta I., \& Granieri E., (2013): Post-Traumatic Epilepsy: Review. Journal of Neurology \& Neurophysiology p:2-5 S2: 009 doi:10.4172/2155-9562.S2-009Available on: http://www.google.com.au/url?url=http://www. omicsonline.org/post-traumatic-epilepsyreview-2155-9562.S2-

009.pdf\&rct=j\&frm $=1 \& \mathrm{q}=\&$ esrc $=\mathrm{s} \& \mathrm{sa}=\mathrm{U} \& \mathrm{ved}$ $=0$ ahUKEwiEivDG58TOAhXFW5QKHb_ACF YQFggZMAA\&usg=AFQjCNE5R0bSweaHke8 VLeV7hOfoCdnplw

7. Chen J, Ruff R, Eavey $\mathbf{R}$ and Wasterlain C. (2009). Posttraumatic epilepsy and treatment. Journal of Rehabilitation Research \& Development: 46 (6). Available on: http://www.rehab.research.va.gov/jour/09/46/6/ Chen.html

8. Choi I., Park H., Chang J., Cho S., Choi S., \& Byun B., (2008): Clinical factors for the development of posttraumatic hydrocephalus after decompressive craniectomy. J Korean Neurosurg Soc; 43:227-31. Available on: https://www.ncbi.nlm.nih.gov/pmc/articles/PM C2588218/

9. Cuthbert J., Harrison-Felix C., Corrigan J., Kreider S., Bell J., Coronado V., \& Whiteneck G., (2015): Epidemiology of Adults Receiving Acute Inpatient Rehabilitation for a Primary Diagnosis of Traumatic Brain Injury in the United States. J Head Trauma Rehabil;30 (2), pp. 122-135

10. De-BLeser L., Depritere R., De-Waele K., Vanhaecht K., Vlayen J., \& Sermeus W., (2006): Defining pathways. Journal of Nursing Management; 14:553-63

11. De-Luc K., Kitchiner D., Layton A., Morris E., Murray Y., \& Overill S., (2001): Developing Care Pathways: the Handbook. 1st edit. Radcliffe Medical Press Ltd, Oxon; 19

12. Evensen A., Sanson-Fisher R., \& E'Este C., (2010): Trends in publications regarding evidence-practice gaps: a literature review. Implement Sci; 5: 11.

13. Evik S., Bosnak V., Namiduru M., Karaoglan I., \& Ozlem M., (2013): Invasive deviceassociated hospital infection rates, etiological agents, and their antibiotic susceptibilities in the medical intensive care unit of a university hospital in Turkey. Turkish Journal of Medical Sciences, 43: 33-38 http://journals.tubitak.gov.tr/medical/issues/sag13-43-1/sag-43-1-7-1203-25.pdf

14. Frieden T., Houry D., and Baldwin G., (2015): Traumatic brain injury in United States: epidemiology and rehabilitation. Centers for Disease Control and Prevention (CDC). United States. Pp.16-17.

15. Ibrahim A., Okasha M., \& Elwany S., (2016): Endoscopic endonasal multilayer repair of traumatic CSF rhinorrhea. Eur Arch Otorhinolaryngol 273:921-926

16. Kennedy P., Leathley M., \& Hughes F., (2010): Clinical practice variation. MJA; 193 (8). 193: S97-S99. Available on: https://www.mja.com.au/journal/2010/193/8/cli nical-practice-variation

17. Lau C., (2014): Nurse coordinated CABG Clinical Pathway resulting in Shortening of Hospital Length of Stay and Improvement in Clinical Outcomes. Available on: https://www.ha.org.hk/haconvention/hac2014/pr oceedings/downloads/SPP5.2.pdf. Retrieved on 21/12/2015

18. Liu B., (2015): Current status and development of traumatic brain injury treatments in China. Chinese Journal of Traumatology; 18: 135-136.

19. Lombard L., \& Zafonte R., (2005): Agitation after Traumatic Brain Injury. American Journal of PhysicalMedicine \& Rehabilitation, 84(10) 797- 812

20. Loveday H., Wilson J., Pratt R., Golsorkhi M., Tingle A., (2014): National Evidence-based Guidelines For Preventing Healthcare Associated Infections in NHS hospitals in England. Department of Health EPIC 3. Journal of Hospital Infection. 86S1 (s1-70). https://www.his.org.uk/files/3113/8693/4808/ep ic3_National_Evidence-

Based_Guidelines_for_Preventing_HCAI_in_N HSE.pdf

21. Moyen E., Camiré E., \& Stelfox H., (2008): Clinical review: Medication errors in critical care. Crit Care, 8; 12(2): 208. http://www.ncbi.nlm.nih.gov/pmc/articles/PMC 2447555/

22. Michael M., Krausz, Itamar Ashkenazi , \& Jean F., (2014): Soustiel. Trauma Surgery (Acute Traumatic Brain Injuries and Their Management) . Springer-Verlag Italia, e-book. P.p 165-181.

23. Nor M., Abdul rahman N., \& Adnan J., (2013): Letter to Editor: Post-Traumatic 
Hydrocephalus. Malays J Med Sci; 20 (1): $95-$ 96. Avaible on: https://www.mjms.usm.my

24. Pandor A., Goodacre S., Harnan S., Holmes M., Pickering A., Fitzgerald P., Rees A., \& Stevenson M., (2011): Diagnostic management strategies for adults and children with minor head injury: a systematic review and an economic evaluation. Health Technology Assessment; Vol. 15: No. 27.p.p 1366-5278

25. Peter L., Linnemanna M., \& Tibæka M., (2013): Hydrocephalus following severe traumatic brain injury in adults. Incidence, timing, and clinical predictors during rehabilitation. NeuroRehabilitation: 33: 473480.

26. Pilgrim J., Gerostamoulos D., \& Drummer O., (2014): "King hit" fatalities in Australia, 2000-2012: The role of alcohol and other drugs. Journal of mental health and prevention, 135, Pages 119-132.

http://www.drugandalcoholdependence.com/arti cle/S0376-8716(13)00498-5/pdf

27. Prosser D., Vender J., \& Solares A., (2011): Traumatic Cerebrospinal Fluid Leaks Otolaryngol Clin N Am; (44): 857-873. http://www.google.com.au/url?url=http://www. hopkinsmedicine.org/otolaryngology/education/ thursday_lecture_series/traumatic $\% 2520 \mathrm{CSF} \% 2$ 520leaks.pdf\&rct=j\&frm $=1 \& q=\& e s r c=s \& s a=U$ \&ved=0ahUKEwjH3-jDsTOAhWBk5QKHby1DM4QFggZMAA\&usg= AFQjCNF7kVX2bZEYcv4_eqLi2frch-KcqA

28. Ramon A., \& Vos P., (2015): Traumatic brain injury. John Wiley \& Sons, Ltd. Oxford. British Library Ebook. P.P (96-98)

29. Rangel-Castillo L., Gopinath S., \& Robertson C., (2008): Management of Intracranial Hypertension. Neurologic clinics; 26(2):521541. Doi:10.1016/j.ncl.2008.02.003. Available on:

http://www.ncbi.nlm.nih.gov/pmc/articles/PMC 2452989/

30. Rotter T., Kinsman L., James E., Machotta A., Gothe H., Willis J., Snow P., \& Kugler J., (2010): Clinical pathways: effects on professional practice, patient outcomes, length of stay and hospital costs (Review). The Cochrane library (7): 1-166.

31. Rotter T., Kugler J., Koch R., Gothe H., Twork S., (2008): A systematic review and meta-analysis of the effects of clinical pathways on length of stay, hospital costs and patient outcomes. BMC Health Services Research, $8: 265$.

http://bmchealthservres.biomedcentral.com/artic les/10.1186/1472-6963-8-265
32. Roytowski D., \& Figaji A., (2013): Raised intracranial pressure: What it is and how to recognise it. CME; 31 (3): p 85-90. Available on:

http://www.ajol.info/index.php/cme/article/dow nload/87803/77457

33. Ruff R., \& Riechers R., (2012): Effective Treatment of Traumatic Brain Injury. American Medical Association J (JAMA); 308 (19). P.p 2032-33.

34. Sankhyan N., Raju V., Sharma S., \& Gulati S., (2010): Management of Raised Intracranial Pressure. Indian J Pediatric; 77:1409-1416.

35. Sarkari A., Gupta D., Sinha S., Kale S., \& Mahapatra A., (2010): Post-traumatic hydrocephalus: Presentation, management and outcome - An apex trauma centre experience. Indian Journal of Neurotrauma (IJN13T5); 7 (2): pp. 135-138. Available on: http://medind.nic.in/icf/t10/i2/icft10i2p135.pdf.

36. Teasell R., Bayona N., Lippert C., Villamere J., \& Hellings C., (2007): Post-traumatic seizure disorder following acquired brain injury. See comment in PubMed Commons belowBrain Inj.; 21(2): 201-14. Available on: http://www.tandfonline.com/doi/full/10.1080/02 699050701201854

37. Tülin A., \& Nihan O., (2012): Intensive Care Management of the Traumatic Brain Injury, Emergency Medicine - An International Perspective, Dr. Michael Blaivas (Ed.), ISBN: 978-953-51-0333-2, InTech, Available from: http://www.intechopen.com/books/emergencymedicine-an-internationalperspective/intensivecare-management-of-the-traumatic-brain-injury.

38. Walker C., Danby S., \& Turner S., (2012): Impact of a bronchiolitis clinical care pathway on treatment and hospital stay. European Journal of Pediatrics, 171 (5), pp 827-832. http://link.springer.com.access.library.unisa.edu. au/article/10.1007/s00431-011-1653-9.

39. White A., (2012): Long-Term Mechanical Ventilation: Management Strategies. RESPIRATORY CARE; 57 (6), P: 889- 899. http://rc.rcjournal.com/content/57/6/889.full.pdf + html. 